\title{
Three years of growth hormone treatment in young adults with Prader-Willi Syndrome previously treated with growth hormone in childhood: Effects on glucose homeostasis and metabolic syndrome
}

\author{
Layla Damen ${ }^{1,2,3,4}$ (D) | Lionne N. Grootjen ${ }^{1,2,3,4}$ | Stephany H. Donze $e^{1,2,3,4}$ (i) | \\ Alicia F. Juriaans $^{1,2,3,4}$ | Laura C. G. de Graaff ${ }^{3,4,5}$ | Janielle A.E.M. van der Velden ${ }^{4,6}$ | \\ Anita C. S. Hokken-Koelega ${ }^{1,2,3,4}$
}

${ }^{1}$ Dutch Growth Research Foundation, Rotterdam, The Netherlands

${ }^{2}$ Department of Pediatrics, Subdivision of Endocrinology, Erasmus University Medical Center-Sophia Children's Hospital, Rotterdam, the Netherlands

${ }^{3}$ Academic Center for Rare Growth Disorders, Erasmus University Medical

Center, Rotterdam, the Netherlands

${ }^{4}$ Dutch Reference Center for Prader-Willi Syndrome, The Netherlands

${ }^{5}$ Internal medicine, Division of Endocrinology, Erasmus University Medical Center, Rotterdam, the Netherlands

${ }^{6}$ Department of Pediatrics, Subdivision of Endocrinology, Radboud University Medical Center, Amalia Children's Hospital, Nijmegen, The Netherlands

\section{Correspondence}

Layla Damen, Dutch Growth Research Foundation, Westzeedijk 106, 3016 AH Rotterdam, The Netherlands.

Email: I.damen@kindengroei.nl

\section{Funding information}

This study was an investigator-initiated study, supported by an independent research grant from Pfizer. Pfizer was not involved in conception or design of the study, nor in collection, analysis or interpretation of data, writing the manuscript, or decision to submit the manuscript for publication.

\begin{abstract}
Context: Growth hormone (GH) has been approved for children with Prader-Willi syndrome (PWS) and significantly improves body composition in adults with PWS. Adults with PWS are predisposed to develop impaired glucose tolerance (IGT) and diabetes mellitus type 2 (DMT2). Continuation of GH maintains body composition, but $\mathrm{GH}$ is known to induce insulin resistance, which might affect glucose homeostasis. Studies on long-term effects of $\mathrm{GH}$ treatment in adults are very limited.

Objective: To investigate effects of 3 years of GH treatment on glucose homeostasis and prevalence of metabolic syndrome (MS) in adults with PWS.

Design: Open-label, prospective study.

Patients: 43 young adults with PWS.

Setting: Dutch PWS Reference Center.

Main outcome measures: Glucose and insulin during oral glucose tolerance test.

Results: Estimated mean $(95 \% \mathrm{Cl})$ fasting glucose and insulin levels remained stable during 3 years of GH treatment. Glucose being $4.6(4.4-4.8) \mathrm{mmol} / \mathrm{l}$ at start and 4.7 (4.6-4.9) $\mathrm{mmol} / \mathrm{l}$ after 3 years $(P=.07)$; insulin being 59.5 (45.2-75.8) $\mathrm{pmol} / \mathrm{l}$ and 56.7 (45.2-69.6) pmol/I resp. $(P=.72)$. Sex, ethnicity and fat mass percentage were significantly associated with fasting glucose levels, while IGF-I or GH-dose were not. Blood pressure, lipids and prevalence of MS remained stable during 3 years of $\mathrm{GH}$. IGT prevalence was variable over time, six patients had IGT at start and eleven after 3 years of GH. One patient developed DMT2. However, prevalence of IGT or DMT2 was not significantly higher after 3 years than at study start.

Conclusions: Three years of GH treatment in adults with PWS does not impair glucose homeostasis and does not lead to an increased prevalence of DMT2.

KEYWORDS

adults, glucose homeostasis, growth hormone, OGTT, Prader Willi syndrome
\end{abstract}




\section{1 | INTRODUCTION}

Prader-Willi syndrome (PWS) is a rare multisystem genetic disorder caused by lack of expression of paternally inherited imprinted genes on the Prader-Willi region of chromosome 15, mostly caused by a paternal deletion or maternal uniparental disomy (mUPD) and in some cases by an imprinting centre defect (ICD) or paternal chromosomal translocation. ${ }^{1,2}$ PWS is characterized by muscular hypotonia, developmental delay, behavioural problems, short stature and hyperphagia which can result in severe obesity when food intake is uncontrolled. ${ }^{2,3}$ Body composition is abnormal with a high body fat percentage and a low lean body mass (LBM). ${ }^{4,5}$

In children with PWS, benefits of growth hormone (GH) treatment are well established. ${ }^{4} \mathrm{GH}$ improves body composition, psychomotor development, cognition, adaptive functioning and linear growth $^{4,6-8}$ without adverse effects on glucose parameters, lipid profile and blood pressure. ${ }^{4,9} \mathrm{GH}$ treatment together with multidisciplinary care from a young age onwards has substantially changed the phenotype of children with PWS. ${ }^{4,10}$

Currently, young adults with PWS have to cease GH treatment at attainment of adult height $(\mathrm{AH})$, if they do not meet the criteria for adult growth hormone deficiency. However, studies have shown that GH treatment is also beneficial for adults with PWS, as discontinuation leads to a deterioration of body composition, while continuation maintains the improved body composition acquired during childhood. ${ }^{11,12}$

Due to their abnormal body composition, adults with PWS are predisposed to develop impaired glucose tolerance (IGT) and diabetes mellitus type 2 (DMT2). ${ }^{13}$ In patients developing DMT2, reported mean age at onset was 20 years. ${ }^{14}$ Prevalence of DMT2 in adults with PWS varies from $7 \%$ to $24 \% .{ }^{14-18} \mathrm{GH}$ is known to induce insulin resistance, ${ }^{19}$ which might further increase the risk for IGT and DMT2. Studies in adults with PWS, who started GH treatment in adulthood, found no negative effects of $\mathrm{GH}$ on glucose homeostasis during 1 year of $\mathrm{GH}^{20-22}$ Our previous randomized, placebo-controlled, cross-over study in young adults with PWS showed a slightly higher fasting glucose and insulin level during 1 year of GH vs 1 year of placebo, but both remained well within normal ranges. ${ }^{23}$

We report the effects of 3 years of continuous $\mathrm{GH}$ treatment on glucose homeostasis in previously $\mathrm{GH}$-treated young adults with PWS who had attained $\mathrm{AH}$. We hypothesized that, during 3 years of $\mathrm{GH}$, glucose and insulin levels would remain stable as negative effects of $\mathrm{GH}$ on glucose metabolism would be counterbalanced by positive effects on body composition. Furthermore, we investigated prevalence of IGT, DMT2 and metabolic syndrome (MS).

\section{2 | METHODS}

\section{1 | Patients}

We included 43 young adults participating in the Dutch Young Adult PWS (YAP) study, coordinated by the Dutch Growth Research
Foundation. Inclusion criteria were as follows: (a) genetically confirmed diagnosis of PWS by positive methylation test; (b) GH treatment for at least 5 years during childhood; (c) at least 3 years of continuous $\mathrm{GH}$ treatment after $\mathrm{AH}$ attainment, which was defined as height velocity less than $0.5 \mathrm{~cm}$ per 6 months and complete epiphyseal fusion. Exclusion criteria were as follows: (a) medication to reduce weight (fat); (b) non-cooperative behaviour; (c) obstructive sleep apnea syndrome.

At attainment of $\mathrm{AH}, \mathrm{GH}$ treatment had to be discontinued as there is no approval for GH treatment for adults with PWS. The YAP Study was started in 2011 to evaluate long-term effects and safety of GH treatment in young adults with PWS who had been treated with GH during childhood. Patients were included in the YAP Study either after participation in the Dutch PWS Cohort Study in children $^{4,24}$ or the Transition study. ${ }^{11,23}$

For patients who participated in the Dutch PWS Cohort Study, GH dose was lowered after $\mathrm{AH}$ attainment from $1 \mathrm{mg} / \mathrm{m}^{2} /$ day $(\sim 0.035 \mathrm{mg} / \mathrm{kg} /$ day $)$ to $0.33 \mathrm{mg} / \mathrm{m}^{2} /$ day $(\sim 0.012 \mathrm{mg} / \mathrm{kg} /$ day $)$. Patients who participated in the Transition Study had been without $\mathrm{GH}$ for a median duration of 1 year before restart of $\mathrm{GH}$ in a dose of $0.33 \mathrm{mg} / \mathrm{m}^{2} /$ day. The aim of present study was to investigate effects of 3 years of $\mathrm{GH}$ with a stable dose. We, therefore, did not analyse the data of the first year after $\mathrm{GH}$ dose lowering of patients who participated in the Cohort Study, nor the data of the first year after $\mathrm{GH}$ restart of patients who participated in the Transition study. We chose to exclude this first year in both groups to eliminate influence of $\mathrm{GH}$ dose lowering or $\mathrm{GH}$ restart.

The study was approved by the Medical Ethics Committee of the Erasmus Medical Centre/ Sophia Children's Hospital, Rotterdam, the Netherlands. Written informed consent was obtained from participants and/or their legal representatives.

\section{2 | Design}

Open-label, prospective study investigating long-term effects and safety of 3 years of $\mathrm{GH}$ with a stable dose. All participants were examined at the Dutch PWS Reference Center in Rotterdam. Patients were treated with $\mathrm{GH}$ in a dose of $0.33 \mathrm{mg} / \mathrm{m}^{2} /$ day $(\sim 0.012 \mathrm{mg} / \mathrm{kg} /$ day). Dose was adjusted based on calculated body surface area and serum IGF-I levels between 1 and 2 SDS. Patients were examined every 6 months by the PWS team of the Dutch Growth Research Foundation, which is a multidisciplinary team consisting of a physician, nurse, psychologist, dietitian and a physiotherapist.

\section{3 | Measurements}

Standing height was measured in centimetres with a calibrated Harpenden stadiometer. Body weight was measured in kilograms on an electric calibrated scale (Servo Balance KA-20-150S; Servo Berkel Prior, Katwijk, The Netherlands). Height, weight and body mass index (BMI) were expressed as standard deviations scores (SDS) using 
GrowthAnalyser version 4.0 (available at www.growthanalyser.org), adjusted for sex and age according to Dutch reference values. ${ }^{25,26}$ Systolic and diastolic blood pressure (BP) were measured once according to standard operating procedure with an automatic blood pressure monitor using an appropriately sized cuff while patients were in sitting position. Fat mass percentage (FM\%) and lean body mass (LBM) were measured by DXA (Lunar Prodigy type; GE Healthcare, Chalfont St. Giles, UK). Family history was assessed by questionnaires filled out by parents of participants. A positive family history for DMT2 was classified as a parent or grandparent having the condition.

\subsection{Endocrine and metabolic investigations}

After overnight fasting, blood samples were collected for assessment of serum IGF-I, total cholesterol, HDL cholesterol (HDLc) and LDL cholesterol (LDLC). A standard 75-g oral glucose tolerance test (OGTT) was performed every year during the 3-year study.

To evaluate overall responses to oral glucose load, apart from plasma levels at various time points, 120-minutes area under the curve (AUC) for time-concentration for glucose and insulin was calculated using the trapezoidal rule. Insulin/glucose ratio at 30 and 120 minutes and homeostasis model assessment (HOMA-IR), calculated as insulin $(\mu \mathrm{U} / \mathrm{ml}) \times$ blood glucose $(\mathrm{mmol} / \mathrm{l}) / 22.5,{ }^{27}$ were used as an index of relative insulin resistance. IGT was defined as a glucose level at 2 hours after glucose load between 7.8 and $11.0 \mathrm{mmol} / \mathrm{l}$. DMT2 was defined as a fasting glucose $\geq 7.0 \mathrm{mmol} / \mathrm{l}$ or a 2 -hour glucose $\geq 11.1 \mathrm{mmol} / \mathrm{I}$ according to WHO guideline. ${ }^{28}$

\section{5 | Assays}

Blood samples were measured in the Biochemical and Endocrine laboratories of the Erasmus Medical Centre, Rotterdam. Glucose and insulin were assayed immediately. Insulin levels were assessed using the Immulite 2000 assay (Siemens Healthcare Diagnostics) until 2018. In 2019 and 2020, insulin levels were assessed using Lumipulse G1200. A correction factor, provided by the laboratory, was used for insulin levels measured by the new assay. Glucose levels were determined using the Hitachi 917 (Hitachi Device Development Center), detecting glucose levels between 0 and $42 \mathrm{mmol} / \mathrm{l}$. Serum IGF-I levels were assessed using the Immulite 2000 (Siemens Health-care Diagnostics, Deerfield, IL) until 2013, with interassay CV of 6.5\%. After 2013, IGF-I was measured using the IDS-iSYS (Immunodiagnostic Systems), with an interassay $\mathrm{CV}$ of $<6.0 \%$ and intra-assay $\mathrm{CV}$ of $<2.1 \%$. Levels of IGF-I were expressed as SDS, adjusting for age and gender. ${ }^{29}$

\section{6 | Metabolic syndrome}

Criteria of the National Cholesterol Education Program (NCEP; Adult Treatment Panel III) were used to determine components of MS. ${ }^{30}$
Patients having 3 or more of the following risk factors were classified as having MS: (a) Waist circumference in men greater than $102 \mathrm{~cm}$, and in women greater than $88 \mathrm{~cm}$; (b) TG $>1.7 \mathrm{mmol} / \mathrm{l}$, or treatment for high TG; (c) HDL-cholesterol in men $<1.03$, in women $<1.3 \mathrm{mmol} / \mathrm{l}$, or treatment to increase HDL-cholesterol; (d) systolic BP $\geq 130$ or diastolic BP $\geq 85 \mathrm{mmHg}$, or treatment for hypertension; (e) Fasting glucose $\geq 5.6 \mathrm{mmol} / \mathrm{l}$ or treatment for elevated blood glucose.

\section{7 | Statistics}

Statistical analyses were performed with SPSS version 24.0 (SPSS Inc). Variables are presented as mean (standard deviation) in case of normally distributed variables and as median (interquartile range [IQR]) in case a variable was not normally distributed. Changes over time were calculated using linear mixed model analysis with outcomes measured at each time point as dependent variable with an unstructured covariance matrix. In one patient, OGTT after 3 years was not performed because of development of DMT2. We therefore included the abnormal OGTT results during the previous years of this patient in mixed models to avoid bias. In case a variable was not normally distributed, variables were transformed, by either square root transformation or log transformation prior to analyses. Effects are presented as estimated marginal mean $(95 \% \mathrm{Cl})$. Multiple linear regression analyses were performed to investigate association of sex, family history, ethnicity, SSRT use, and GH-dose or IGF-I SDS with fasting and 2-hour plasma glucose, both at study start and after 3 years. Independent samples $t$ tests and Fisher's Exact tests were used to investigate differences in abnormal glucose tolerance (either IGT or DMT2) at start and after 3 years between groups. McNemar's test was used to compare the prevalence of abnormal glucose tolerance at start with prevalence after 3 years. Differences were considered significant if $P$-value was $<.05$.

\section{3 | RESULTS}

\subsection{Characteristics at start of the 3-year study}

Forty-three young adults with PWS (18 males, 25 females) were included (Table 1). Median (IQR) age was 19.5 (18.7-20.7) years for males and 18.4 (16.9-20.8) years for females. Median (IQR) height was $-1.0(-1.7$ to -0.3$)$ SDS and BMI $24.5(21.9-27.7) \mathrm{kg} /$ $\mathrm{m}^{2}$, being $0.9(0.0-1.8)$ SDS. All patients had been treated with $\mathrm{GH}$ during childhood. Eighteen (41.9\%) patients had a deletion, twenty (46.5\%) an mUPD, four (9.3\%) an ICD and one (2.3\%) a translocation. Thirty-three patients received sex steroid replacement therapy (SSRT) during the study, while ten did not. Three of the patients who did not receive SSRT were classified as being eugonadal, while seven were hypogonadal. Not prescribing SSRT in these patients was a mutual decision between physician and caregivers based on patient characteristics at that moment (eg behavioural or weight problems). 


\section{2 | Glucose homeostasis during 3 years of $\mathrm{GH}$ treatment}

TAB LE 1 Clinical characteristics at start of 3 year study

\begin{tabular}{|c|c|c|}
\hline Number (females) & $43(25)$ & \\
\hline \multicolumn{3}{|l|}{ Genetic subtype } \\
\hline $\begin{array}{l}\text { Deletion/mUPD/ICD/ } \\
\text { translocation }\end{array}$ & $18 / 20 / 4 / 1$ & \\
\hline $\begin{array}{l}\text { Age at start of childhood GH } \\
\text { treatment (yrs) }\end{array}$ & 7.6 & (5.2 to 10.1$)$ \\
\hline \multicolumn{3}{|l|}{ Age at inclusion (yrs) } \\
\hline Males & 19.5 & (18.7 to 20.7 ) \\
\hline Females & 18.4 & (16.9 to 20.8 ) \\
\hline Adult height (SDS) & -1.0 & $(-1.7$ to -0.3$)$ \\
\hline $\mathrm{BMI}\left(\mathrm{kg} / \mathrm{m}^{2}\right)$ & 24.5 & (21.9 to 27.7 ) \\
\hline BMI for age (SDS) & 0.9 & (0.0 to 1.8$)$ \\
\hline BMI for PWS (SDS) & -1.4 & $(-2.0$ to -0.7$)$ \\
\hline Fasting glucose (mmol/l) & 4.6 & (4.1 to 4.9$)$ \\
\hline Fasting insulin (pmol/l) & 55.0 & (35.5 to 68.0 ) \\
\hline IGF-I SDS ${ }^{a}$ & 1.5 & (0.6 to 2.0$)$ \\
\hline
\end{tabular}

Note: Data expressed as median (IQR), mUPD, maternal uniparental disomy; ICD, imprinting center defect.

aGF-I SDS was calculated according to age- and sex-matched Dutch references.
Table 2 shows carbohydrate parameters during 3 years of GH treatment. Estimated mean $(95 \% \mathrm{Cl})$ fasting glucose levels remained stable during 3 years of $\mathrm{GH}$, being $4.6(4.4-4.8) \mathrm{mmol} / \mathrm{l}$ at start and 4.7 (4.64.9) $\mathrm{mmol} / \mathrm{l}$ after 3 years $(P=.07)$. Estimated mean $(95 \% \mathrm{Cl})$ fasting insulin levels remained also stable, being $59.5(45.2-75.8) \mathrm{pmol} / \mathrm{l}$ at start and $56.7(45.2-69.6) \mathrm{pmol} / \mathrm{l}$ after 3 years $(P=.72)$. Glucose at 2 hours after glucose load increased from $6.4(5.8-7.0) \mathrm{mmol} / \mathrm{l}$ at start to 7.0 (6.4-7.6) $\mathrm{mmol} / \mathrm{I}$ after 3 years, but not significantly $(P=.07)$. Other carbohydrate parameters also remained stable during 3 years.

Figure 1 shows plasma glucose and insulin levels before and 30 , 60, 90 and 120 minutes after glucose load at different timepoints during the 3-year study. All glucose and insulin levels after 3 years of $\mathrm{GH}$ were similar to levels at start. Only estimated mean $(95 \% \mathrm{Cl})$ fasting glucose after 2 years was significantly higher (4.8 (4.6-4.9)) $\mathrm{mmol} / \mathrm{I}$ than at start $(4.6(4.4-4.8) \mathrm{mmol} / \mathrm{I}, P=.018)$. All other glucose and insulin levels at other timepoints were similar to levels at start.

\subsection{Associations with glucose metabolism}

Table 3 shows the results of multiple regression analysis.

Fasting glucose both at study start and after 3 years was significantly associated with sex and ethnicity. Male gender was associated with a higher fasting glucose at study start and after 3 years $(\beta=0.702$,

TABLE 2 Metabolic health parameters during the 3 year study

\begin{tabular}{|c|c|c|c|c|c|}
\hline & At start & After 1 year & After 2 years & After 3 years & $\begin{array}{l}P \text { - } \\
\text { value* }\end{array}$ \\
\hline \multicolumn{6}{|l|}{ Carbohydrate data } \\
\hline Fasting glucose (mmol/l) & $4.6(4.4-4.8)$ & $4.7(4.5-4.9)$ & $4.8(4.6-4.9)$ & $4.7(4.6-4.9)$ & .07 \\
\hline $\begin{array}{l}\text { Glucose } 2 \mathrm{~h} \text { after glucose load } \\
(\mathrm{mmol} / \mathrm{l})\end{array}$ & $6.4(5.8-7.0)$ & $6.6(6.0-7.1)$ & $6.8(6.2-7.4)$ & $7.0(6.4-7.6)$ & .07 \\
\hline AUC glucose $\left(\mathrm{mmol} / \mathrm{I}^{*} 120 \mathrm{~min}\right)$ & $872.8(807.6-938.0)$ & 876.9 (816.2-937.5) & $\begin{array}{l}934.8 \\
(859.4-1010.2)\end{array}$ & $\begin{array}{l}918.6 \\
(846.9-990.3)\end{array}$ & .16 \\
\hline Fasting insulin (pmol/l) & $59.5(45.2-75.8)$ & $67.6(55.0-81.5)$ & $63.8(51.1-77.9)$ & $56.7(45.2-69.6)$ & .72 \\
\hline Insulin $2 \mathrm{~h}$ after glucose load (pmol/I) & $\begin{array}{l}340.1 \\
(283.9-401.4)\end{array}$ & $334.2(263.5-419.4)$ & $317.1(265.1-376.2)$ & $352.8(279.9-434.1)$ & .72 \\
\hline AUC insulin $\left(\mathrm{pmol} / \mathrm{I}^{*} 120 \mathrm{~min} * 10^{3}\right.$ & $40.2(34.0-47.5)$ & $43.7(36.4-52.4)$ & $42.7(38.3-47.6)$ & $37.2(31.5-43.9)$ & .42 \\
\hline Ratio ins/gluc at $30 \mathrm{~min}$ & $44.6(36.0-55.2)$ & $46.9(39.2-56.9)$ & $43.8(37.6-50.9)$ & $41.9(34.3-51.2)$ & .52 \\
\hline Ratio ins/gluc at $120 \mathrm{~min}$ & $52.2(42.4-64.4)$ & $45.8(36.8-57.0)$ & $43.2(34.8-53.7)$ & $46.9(39.6-55.6)$ & .32 \\
\hline HOMA-IR & $1.7(1.3-2.2)$ & $2.0(1.6-2.4)$ & $1.9(1.5-2.4)$ & $1.7(1.3-2.1)$ & .82 \\
\hline \multicolumn{6}{|l|}{ Blood pressure } \\
\hline Systolic blood pressure & $119.8(116.1-123.6)$ & $123.8(120.5-127.1)$ & $122.9(118.9-127.0)$ & $122.3(118.2-126.3)$ & .36 \\
\hline Diastolic blood pressure & $73.2(70.5-75.9)$ & $73.1(71.1-75.0)$ & $74.3(72.0-76.5)$ & $72.8(70.2-75.3)$ & .80 \\
\hline \multicolumn{6}{|l|}{ Lipids } \\
\hline Total cholesterol (mmol/l) & $4.6(4.4-4.9)$ & $4.7(4.4-4.9)$ & $4.6(4.3--4.8)$ & $4.6(4.4-4.8)$ & .71 \\
\hline LDL cholesterol (mmol/l) & $3.0(2.7-3.2)$ & $3.1(2.8-3.3)$ & $3.0(2.8-3.2)$ & $3.0(2.8-3.2)$ & .51 \\
\hline HDL cholesterol (mmol/I) & $1.4(1.3-1.4)$ & $1.4(1.3-1.5)$ & $1.3(1.2-1.4)$ & $1.3(1.3-1.4)$ & .93 \\
\hline Triglycerides (mmol/l) & $0.95(0.83-1.09)$ & $0.93(0.82-1.05)$ & $1.03(0.91-1.16)$ & $0.96(0.83-1.12)$ & .82 \\
\hline
\end{tabular}

Note: Data are expressed as estimated means $(95 \% \mathrm{CI})$. AUC, area under the curve; ins/gluc, ratio of insulin/glucose; HOMA-IR, homeostatic model assessment of insulin resistance.

$P$-value of the change during three years of $\mathrm{GH}$ treatment. 

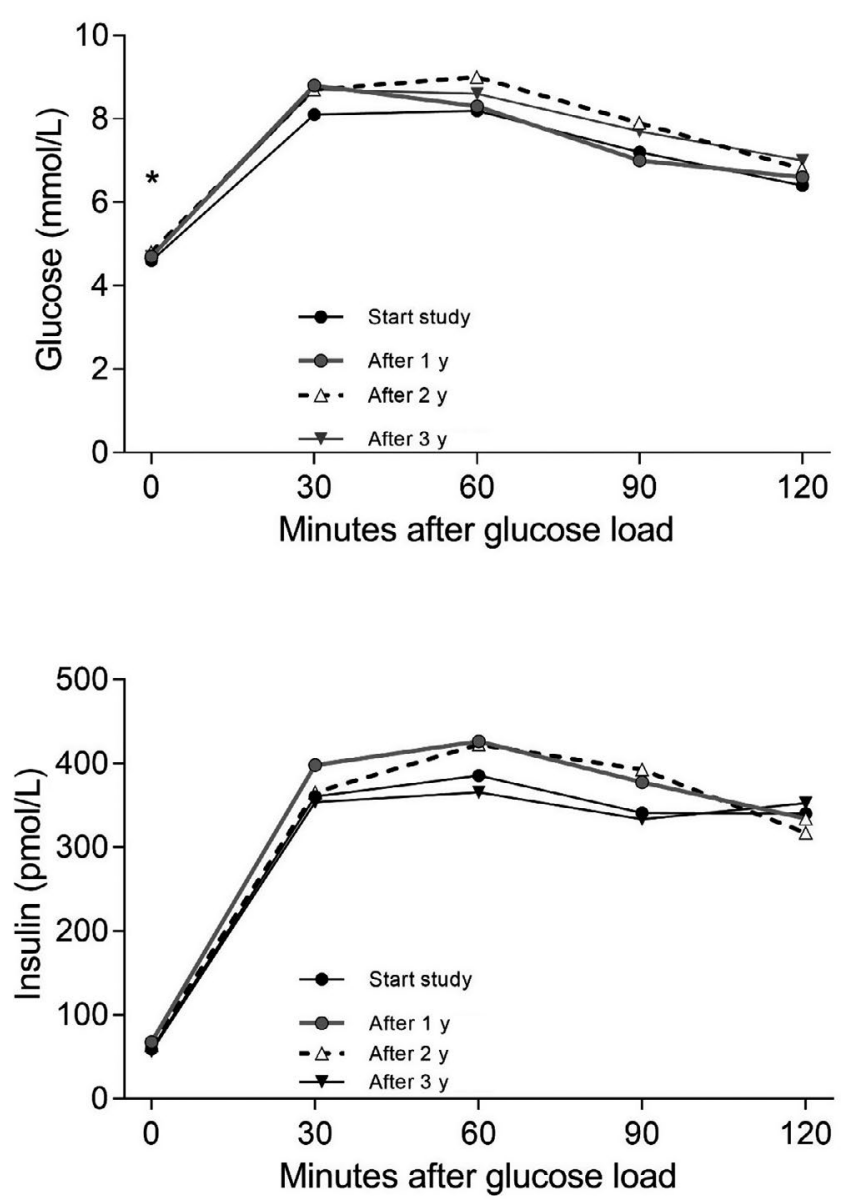

FIGURE 1 Glucose and insulin levels during oral glucose tolerance test. Estimated mean glucose and insulin levels during OGTT at study start (black circles), after 1 year (grey circles), after 2 years (white triangles) and after 3 years (black triangles) of 43 young adults with PWS. *2 year vs start $P$-value $<.05$, other not significantly different
$P<.001$ and $\beta=0.526, P=.008$ resp.), regardless of ethnicity, $\mathrm{FM} \%$ or family history, indicating that male gender results in a $0.702 \mathrm{mmol} / \mathrm{I}$ higher fasting glucose at study start and a $0.526 \mathrm{mmol} / \mathrm{I}$ higher fasting glucose after 3 years. Non-Caucasian ethnicity (eg Moroccan, Hindu or Surinamese) was associated with a higher fasting glucose both at study start and after 3 years of $\mathrm{GH}(\beta=0.609, P=.011$ and $\beta=0.654$, $P=.027$, resp.). Total body FM\% was also associated with fasting glucose, but only at start, indicating an increase of $0.023 \mathrm{mmol} / \mathrm{l}$ in glucose with each $1 \%$ increase in total body FM\%. A model with sex, ethnicity, FM\% and family history positive for DMT2 had an adjusted $R$ square of .482 for fasting glucose at start, indicating that $48 \%$ of variability in fasting glucose levels at start is explained by these factors.

Two-hour glucose at study start was significantly associated with ethnicity $(\beta=3.485, P=.001)$ and total body FM\% $(\beta=0.068$, $P=.047$ ). After 3 years of $\mathrm{GH}$, we found no significant predictors for 2-hour glucose levels.

Adding age, SSRT use, and IGF-I SDS or GH-dose to any of the models did not show a significant association of these variables and did not improve adjusted $\mathrm{R}$ square values.

\subsection{IGT and DMT2 during 3 years of GH treatment}

Clinical characteristics of individual patients with IGT or DMT2 during the study are shown in Table 4.

IGT was present in 6 patients at study start. After 1 year, one of these patients had a normal OGTT and 9 had IGT. After 2 years, 2 patients with IGT after 1 year had returned to normal glucose tolerance and 10 had IGT. At the end of the 3-year study, a total of 11 patients met the criteria for IGT.

DMT2 was present in 1 patient at study start, based on a 2-hour glucose level of $12.5 \mathrm{mmol} / \mathrm{l}$. This patient did not have
TABLE 3 Multiple regression analysis for fasting glucose and 2-hour glucose at study start and after 3 years

\begin{tabular}{|c|c|c|c|c|c|c|c|c|}
\hline & \multicolumn{4}{|c|}{ Study Start } & \multicolumn{4}{|c|}{ After 3 years } \\
\hline & \multicolumn{2}{|c|}{ Fasting glucose } & \multicolumn{2}{|c|}{ 2-hour glucose } & \multicolumn{2}{|c|}{ Fasting glucose } & \multicolumn{2}{|c|}{ 2-hour glucose } \\
\hline & $\beta$ & $P$ & $\boldsymbol{\beta}$ & $P$ & $\boldsymbol{\beta}$ & $P$ & $\beta$ & $P$ \\
\hline Sex & -0.702 & $<.001$ & -0.219 & .722 & -.526 & .008 & 1.210 & .092 \\
\hline Ethnicity & 0.609 & .011 & 3.485 & .001 & .654 & .027 & 1.640 & .191 \\
\hline FM\% & 0.023 & .006 & 0.068 & .047 & .014 & .185 & 0.054 & .177 \\
\hline $\begin{array}{l}\text { Family } \\
\text { history }\end{array}$ & 0.235 & .060 & 0.465 & .369 & .058 & .704 & 0.368 & .517 \\
\hline $\begin{array}{l}\text { Model } \\
P \text {-value }\end{array}$ & $<0.001$ & & 0.001 & & .009 & & 0.015 & \\
\hline $\begin{array}{l}\text { Adjusted } R \\
\text { square }\end{array}$ & 0.482 & & 0.330 & & .239 & & 0.219 & \\
\hline
\end{tabular}

Note: Values presented are results of multiple regression. $\beta=$ unstandardized regression coefficient.

Sex: 1 = men 2 = women. Ethnicity: 0 = caucasian $1=$ noncaucasian. Family history for diabetes mellitus type $2: 0=$ no family history $1=$ positive family history.

$\mathrm{FM} \%=$ total body fat mass percentage. Bolded $\mathrm{p}$-values are significant. 
TAB LE 4 Characteristics of individual patients with impaired glucose tolerance or diabetes mellitus type 2 during the study

\begin{tabular}{|c|c|c|c|c|c|c|c|c|c|c|c|}
\hline \multirow[b]{3}{*}{ Patient } & \multirow[b]{3}{*}{ Sex } & \multirow[b]{3}{*}{ Fam } & \multirow[b]{3}{*}{ Ethnicity } & \multicolumn{8}{|c|}{ Stage of the study } \\
\hline & & & & \multicolumn{5}{|c|}{ Start Study } & \multicolumn{3}{|c|}{ After 1 year } \\
\hline & & & & $\begin{array}{l}\text { Fasting } \\
\text { glucose } \\
\text { (mmol/l) }\end{array}$ & $\begin{array}{l}\text { 2-hour } \\
\text { glucose } \\
\text { (mmol/l) }\end{array}$ & BMI & $\begin{array}{l}\text { FM\% } \\
\text { (\%) }\end{array}$ & $\begin{array}{l}\text { SSRT } \\
\text { use }\end{array}$ & $\begin{array}{l}\text { Fasting } \\
\text { glucose } \\
\text { (mmol/l) }\end{array}$ & $\begin{array}{l}\text { 2-hour } \\
\text { glucose } \\
\text { (mmol/l) }\end{array}$ & BMI \\
\hline 1 & M & + & noncauc & 6.0 & 12.5 & 28.6 & 41.0 & + & 6.2 & 10.9 & 27.5 \\
\hline 2 & $\mathrm{~F}$ & + & cauc & 4.8 & 9.1 & 24.8 & 43.7 & + & 4.8 & 9.6 & 25.9 \\
\hline 3 & M & + & noncauc & 5.2 & 7.8 & 19.6 & 27.0 & + & 5.3 & 8.2 & 18.6 \\
\hline 4 & $\mathrm{~F}$ & + & cauc & 4.4 & 8.9 & 22.3 & 37.1 & + & 4.7 & 8.3 & 23.5 \\
\hline 5 & $\mathrm{~F}$ & - & noncauc & 4.8 & 8.6 & 22.7 & 44.7 & - & 4.9 & 6.5 & 25.0 \\
\hline 6 & $M$ & - & cauc & 4.9 & 8.6 & 19.9 & 36.5 & + & 4.7 & 8.7 & 19.9 \\
\hline 7 & M & + & cauc & 5.4 & 8.9 & 24.2 & $\mathrm{~N} / \mathrm{A}$ & + & 4.5 & 8.2 & 24.6 \\
\hline 8 & M & + & cauc & 4.2 & 6.9 & 19.1 & 28.2 & + & 4.6 & 8.2 & 21.8 \\
\hline 9 & $\mathrm{~F}$ & - & cauc & 4.0 & 5.7 & 24.7 & 42.1 & - & 5.0 & 10.0 & 28.4 \\
\hline 10 & $M$ & - & cauc & 4.4 & 7.3 & 20.2 & 18.0 & + & 4.4 & 8.3 & 19.9 \\
\hline 11 & $\mathrm{~F}$ & - & cauc & 3.7 & 5.9 & 20.0 & 29.2 & + & 4.0 & 6.2 & 22.1 \\
\hline 12 & $\mathrm{~F}$ & - & cauc & 4.0 & 3.2 & 21.1 & 37.9 & + & 4.6 & 6.0 & 20.9 \\
\hline 13 & $\mathrm{~F}$ & + & cauc & 5.3 & 5.2 & 24.2 & 42.3 & - & 5.0 & 6.7 & 26.0 \\
\hline 14 & $\mathrm{~F}$ & - & cauc & 3.8 & 7.2 & 36.6 & 53.3 & + & 5.8 & 7.6 & 40.0 \\
\hline 15 & $\mathrm{~F}$ & - & cauc & 4.0 & 7.0 & 21.5 & 37.4 & + & 4.0 & 7.6 & 21.6 \\
\hline 16 & $\mathrm{~F}$ & + & cauc & 4.1 & 5.5 & 25.4 & 44.4 & + & $\mathrm{N} / \mathrm{A}$ & 6.9 & 26.8 \\
\hline 17 & $\mathrm{~F}$ & - & cauc & 4.8 & $\mathrm{~N} / \mathrm{A}$ & 30.5 & 47.6 & + & 4.8 & 7.1 & 29.7 \\
\hline 18 & $\mathrm{~F}$ & + & cauc & 4.5 & 7.7 & 31.3 & 52.3 & - & 4.2 & 6.5 & 32.2 \\
\hline 19 & $\mathrm{~F}$ & + & cauc & 4.1 & 6.4 & 24.9 & 51.1 & + & $\mathrm{N} / \mathrm{A}$ & 4.8 & 25.2 \\
\hline
\end{tabular}

Note: Fam, positive family history of diabetes mellitus type 2; FM\%, total body fat mass percentage; N/A, not available.

Bolded values represent glucose values $\geq 7.8 \mathrm{mmol} / \mathrm{l}$.

${ }^{a}$ Fasting plasma glucose while treated with Metformin $500 \mathrm{mg}$ twice a day.

${ }^{b} 1$ year after the end of the study 2-hour plasma glucose was $4.1 \mathrm{mmol} / \mathrm{l}$

polyuria or polydipsia and had a fasting glucose of $6.0 \mathrm{mmol} / \mathrm{l}$. The next year, he had a 2-hour glucose level of $10.9 \mathrm{mmol} / \mathrm{l}$, thereby no longer fulfilling the DMT2 criteria. After 2 years, he met the criteria for DMT2 again with a 2 hour glucose of $11.5 \mathrm{mmol} / \mathrm{l}$, without any clinical symptoms and a fasting glucose of $6.1 \mathrm{mmol} / \mathrm{l}$. A few weeks before the 3-year visit, patient was diagnosed with DMT2 with elevated glucose levels and symptoms of polyuria and polydipsia. He was started on Metformin $500 \mathrm{mg}$ twice daily resulting in fasting glucose of $6.6 \mathrm{mmol} / \mathrm{l}$ at follow-up. At the end of the 3-year study, another patient had a 2-hour glucose of $12.1 \mathrm{mmol} / \mathrm{l}$, without clinical symptoms and a fasting glucose of $4.4 \mathrm{mmol} / \mathrm{l}$. This patient had normal glucose tolerance during other years of the study and continued GH treatment after. An OGTT was repeated at 1 year after the 3-year study and showed a 2-hour glucose of $4.1 \mathrm{mmol} / \mathrm{l}$.

The prevalence of IGT or DMT2 was not significantly higher after 3 years than at study start $(P=.18)$. Prevalence of IGT or DMT2 after 3 years was $50.0 \%$ in patients with a positive family history for DMT2 and $21.7 \%$ in patients without $(P=.09)$. Patients with IGT or
DMT2 had a significantly higher mean FM\% of $43.3 \%$ than patients without, who had a mean FM\% of $36.6 \%(P=.02)$.

\section{5 | Metabolic syndrome}

Table 2 shows BP and serum lipids during the 3-year study. Systolic and diastolic BP did not change during the study, neither did serum total cholesterol, LDLc, HDLc and triglycerides.

Table 5 shows different components of MS during the 3-year study. At start, 2 of 37 (5.4\%) patients had three or more MS components, thereby meeting the criteria for MS. After 3 years, this number was the same (5.3\%).

\section{4 | DISCUSSION}

To our knowledge, this is the first prospective, open-label study to describe the effects of 3 years of continuous $\mathrm{GH}$ treatment with a 


\begin{tabular}{|c|c|c|c|c|c|c|c|c|c|c|c|}
\hline FM\% (\%) & $\begin{array}{l}\text { SSRT } \\
\text { use }\end{array}$ & \multicolumn{5}{|c|}{ After 2 years } & \multicolumn{5}{|c|}{ After 3 years } \\
\hline 37.3 & + & 6.1 & 11.5 & 28.8 & 37.8 & + & $6.6^{\mathrm{a}}$ & T2DM & 28.8 & 37.6 & + \\
\hline 23.9 & + & 5.3 & 7.8 & 18.5 & 22.0 & + & 5.3 & 7.8 & 18.9 & 25.0 & + \\
\hline 36.7 & + & 5.0 & 6.0 & 23.1 & 34.6 & + & 4.1 & 6.6 & 21.7 & 34.5 & + \\
\hline 44.6 & - & 4.8 & 7.2 & 25.1 & 45.2 & - & 4.3 & 8.6 & 25.2 & 43.4 & + \\
\hline 38.6 & + & 4.9 & 7.4 & 19.4 & 32.1 & + & 4.9 & 7.3 & 18.7 & 31.4 & + \\
\hline 13.1 & + & 4.9 & 5.9 & 20.0 & 20.7 & + & 4.6 & 6.1 & 20.0 & 19.0 & + \\
\hline 33.7 & + & 4.3 & 7.8 & 22.4 & 37.3 & + & 4.1 & 6.9 & 23.1 & 36.4 & + \\
\hline 38.2 & + & 4.5 & 8.4 & 22.7 & 42.1 & + & 4.3 & 10.5 & 22.2 & 41.4 & + \\
\hline 44.1 & - & 5.5 & 9.2 & 24.9 & 43.7 & - & $\mathrm{N} / \mathrm{A}$ & 6.5 & 25.6 & 41.2 & - \\
\hline 54.2 & + & 5.4 & 10.1 & 43.6 & 54.3 & + & 5.5 & 8.1 & 43.3 & 57.6 & + \\
\hline 39.3 & + & 4.4 & 8.9 & 21.8 & 37.7 & + & 4.5 & 10.7 & 22.4 & 37.8 & + \\
\hline 44.3 & + & 3.9 & $\mathrm{~N} / \mathrm{A}$ & 26.2 & 44.7 & + & 4.4 & $12.1^{b}$ & 27.8 & 46.9 & + \\
\hline 46.2 & + & 4.4 & 8.1 & 28.7 & 44.8 & + & 4.3 & 8.7 & 29.1 & 44.6 & + \\
\hline 51.2 & - & 4.9 & 7.5 & 33.2 & 53.1 & + & 4.0 & 8.6 & 35.9 & 57.0 & + \\
\hline
\end{tabular}

TABLE 5 Metabolic syndrome components during the study according to ATP III criteria (26)

\begin{tabular}{|ccccc|}
\hline Symptoms & At start study & After 1 year & After 2 years & After 3 years \\
\hline $\begin{array}{c}\text { Central Obesity } \\
\text { High triglyceride } \\
\text { levels }\end{array}$ & $8 / 42(19.0 \%)$ & $7 / 41(17.1 \%)$ & $8 / 38(21.1 \%)$ & $6 / 38(15.8 \%)$ \\
\hline $\begin{array}{c}\text { Low HDLc } \\
\text { levels }\end{array}$ & $10 / 42(23.8 \%)$ & $11 / 41(26.8 \%)$ & $13 / 41(31.7 \%)$ & $15 / 40(37.5 \%)$ \\
\hline $\begin{array}{c}\text { High blood } \\
\text { pressure }\end{array}$ & $5 / 41(12.2 \%)$ & $12 / 42(28.6 \%)$ & $12 / 42(28.6 \%)$ & $10 / 40(25.0 \%)$ \\
\hline $\begin{array}{c}\text { High fasting } \\
\text { glucose }\end{array}$ & $1 / 42(2.4 \%)$ & $3 / 40(7.5 \%)$ & $2 / 42(4.8 \%)$ & $2 / 40(5.0 \%)$ \\
\hline $\begin{array}{c}\text { Three or more } \\
\text { MS-symptoms }\end{array}$ & $2 / 37(5.4 \%)$ & $3 / 35(8.6 \%)$ & $4 / 36(11.1 \%)$ & $2 / 38(5.3 \%)$ \\
\hline
\end{tabular}

Note: Number of patients (\%) with MS-symptoms.

Abbreviation: $\mathrm{GH}$, growth hormone. stable median dose of $0.36 \mathrm{mg} / \mathrm{m}^{2} /$ day $(\sim 0.013 \mathrm{mg} / \mathrm{kg} /$ day $)$, on glucose homeostasis in young adults with PWS, who had attained $\mathrm{AH}$ after treatment with $\mathrm{GH}$ for several years during childhood. Our findings demonstrate that fasting and glucose-stimulated glucose and insulin levels during OGTT did not change during 3 years of GH treatment. At study start fasting glucose was associated with sex, 
ethnicity and $\mathrm{FM} \%$, while after 3 years it was associated with sex and ethnicity. Two-hour glucose at start was associated with sex and FM\%, but with none of the variables after 3 years. In multiple linear regression analysis, IGF-I or GH-dose were neither associated with fasting glucose nor with 2-hour glucose, both at start and after 3 years. Blood pressure, serum lipid levels and prevalence of MS remained similar during the 3-year study.

In children with PWS, we showed that fasting glucose levels gradually increased from $4.5 \mathrm{mmol} / \mathrm{I}$ at baseline to $4.8 \mathrm{mmol} / \mathrm{I}$ after 8 years of $\mathrm{GH}$ treatment. ${ }^{4}$ Present study shows that continuation of treatment into adulthood does not further increase fasting glucose levels, which is reassuring. Our results are in line with a 2-year GH study in adults with PWS, showing that levels remained unchanged. ${ }^{31}$

In multiple regression analysis, we found that male gender, regardless of ethnicity, FM\% and family history, was associated with a $0.7 \mathrm{mmol} / \mathrm{l}$ and $0.5 \mathrm{mmol} / \mathrm{l}$ higher fasting glucose at study start and after 3 years, respectively. Non-Caucasian ethnicity was associated with a 0.6 and $0.7 \mathrm{mmol} / \mathrm{I}$ higher fasting glucose at study start and after 3 years, resp., while each 1\% increase in total body FM\% was associated with a $0.02 \mathrm{mmol} / \mathrm{l}$ increase in fasting glucose at start. In contrast, IGF-I SDS or GH-dose were not associated with fasting glucose nor with 2-hour glucose, at study start and after 3 years. These results support our hypothesis that the beneficial effect of $\mathrm{GH}$ on maintaining a stable FM\% might counterbalance the potential effects of $\mathrm{GH}$ on glucose homeostasis.

We found that patients with IGT or DMT2 had a significantly higher FM\% than patients who did not have IGT or DMT2, and prevalence was higher in patients with a positive family history for DMT2 than for those without a positive family history, albeit not statistically significant. Only 3 participants had a non-Caucasian ethnicity, thus it is difficult to draw conclusions. However, it is remarkable that all 3 patients developed either IGT or DMT2. ${ }^{32,33}$

In our study, prevalence of DMT2 was $5.1 \%$, (or $2.6 \%$ when DMT2 based on a single elevated 2-hour plasma glucose level is not taken into account), while a prevalence of $7 \%-24 \%$ is described in literature. ${ }^{14-18}$ It is possible that the young age of our group contributes to the lower prevalence. However, one study reported a prevalence rate of $25 \%$ for DMT2 and a mean age at onset of 20 years. ${ }^{14}$ As the mean age after our 3-year study was 22.5 years, the participants in our study had an age at higher risk for DMT2 development. We, therefore, believe that particularly the relatively low FM\% and relatively high LBM of our study group, as a result of multiple years of $\mathrm{GH}$ treatment during childhood and the continuation of $\mathrm{GH}$ treatment into early adulthood, are responsible for the low prevalence of DMT2 found in current study.

At study start $5.4 \%$ had MS and after 3 years this percentage was similar. Studies investigating MS in PWS are very scarce. One study in adults with PWS found the presence of MS in $4.8 \%$ of non-obese patients and $41.1 \%$ of obese patients. ${ }^{34}$ In our placebo-controlled $\mathrm{GH}$ study, none developed MS during 1 year of $\mathrm{GH}$ treatment, while one developed MS during placebo. ${ }^{23}$ As continuation of $\mathrm{GH}$ prevents deterioration of body composition, it may thereby contribute to prevention of $\mathrm{MS}^{11,12}$
Our study group had a normal median BMI of $24.5 \mathrm{~kg} / \mathrm{m}^{2}$, being $0.9 \mathrm{SDS}$, and a relatively healthy body composition compared to young adults with a classical PWS phenotype. ${ }^{12,35,36}$ We believe that this is the result of $\mathrm{GH}$ treatment during childhood together with multidisciplinary care from a young age onwards. We previously showed that continuation of $\mathrm{GH}$ in early adulthood is able to maintain the improved body composition. ${ }^{12}$ It is, therefore, likely that our results are particularly due to the more healthy condition of our study population and may not be applicable to patients with PWS who are obese. However, two studies investigating GH treatment for a maximum of 2 years in $\mathrm{GH}$-naïve adults with PWS included patients with a mean $\mathrm{BMI}$ of 28.9 and $33.7 \mathrm{~kg} / \mathrm{m}^{2}$. These studies also found no significant adverse effects of $\mathrm{GH}$ on glucose homeostasis. ${ }^{22,31} \mathrm{We}$ expect that in the coming years more patients with PWS will be able to have a healthy BMI, since care for and knowledge of PWS have improved during the last two decades, while GH treatment is currently standard treatment in children with PWS in many countries, and diagnosis is nowadays often made in the first months of life.

Our study did not include a control group of PWS patients not receiving $\mathrm{GH}$ treatment. We did not want to withhold $\mathrm{GH}$ treatment for a longer period in these patients, since about half of the patients participated previously in our randomized, placebo-controlled crossover GH study investigating 1 year of GH vs 1 year of placebo. That study showed a deterioration of body composition during discontinuation of $\mathrm{GH}$ treatment after $\mathrm{AH}^{11}$ and slightly higher fasting glucose and insulin levels during $\mathrm{GH}$ vs placebo, but levels remained within normal range, and glucose-stimulated glucose and insulin levels during OGTT were similar during GH and placebo. ${ }^{23}$ Two other studies investigated effects of 1 year of GH vs placebo in adults with PWS on glucose homeostasis and concluded that 1 year of $\mathrm{GH}$ treatment is safe, ${ }^{22,37}$ but one study did not record GH treatment during childhood $^{37}$ and the other one investigated growth hormone-deficient adults with PWS. ${ }^{22}$

In conclusion, 3 years of continuous GH treatment with a median dose of $0.36 \mathrm{mg} / \mathrm{m}^{2} /$ day $(\sim 0.013 \mathrm{mg} / \mathrm{kg} /$ day $)$ in adults with PWS does not impair glucose homeostasis and does not lead to an increased prevalence of DMT2. The beneficial effect of GH on maintaining a healthier body composition might counterbalance the potential effects of $\mathrm{GH}$ on glucose homeostasis. Our findings show that longer-term GH treatment in young adults with PWS does not pose safety concerns regarding carbohydrate metabolism.

\section{ACKNOWLEDGMENTS}

We express our gratitude to all children and parents for their enthusiastic participation in this study and thank Mariëlle van Eekelen, Laura Schafthuizen and Ezra Piso, research nurses, for all their work. We thank all collaborating paediatric-endocrinologists, paediatricians and other healthcare providers.

\section{DATA AVAILABILITY STATEMENT}

The data that support the findings of this study are available on request from the corresponding author. The data are not publicly available due to privacy or ethical restrictions. 


\section{ORCID}

Layla Damen (iD https://orcid.org/0000-0003-2562-6176

Stephany H. Donze iD https://orcid.org/0000-0002-9249-4284

\section{REFERENCES}

1. Cassidy SB, Driscoll DJ. Prader-Willi syndrome. Eur J Hum Genet. 2009;17(1):3-13.

2. Goldstone AP, Holland AJ, Hauffa BP, Hokken-Koelega AC, Tauber M. Recommendations for the diagnosis and management of PraderWilli syndrome. J Clin Endocrinol Metab. 2008;93(11):4183-4197.

3. Holm VA, Cassidy SB, Butler MG, et al. Prader-Willi syndrome: consensus diagnostic criteria. Pediatrics. 1993;91(2):398-402.

4. Bakker NE, Kuppens RJ, Siemensma EPC, et al. Eight years of growth hormone treatment in children with Prader-Willi syndrome: maintaining the positive effects. J Clin Endocrinol Metab. 2013;98(10):4013-4022.

5. Bekx MT, Carrel AL, Shriver TC, Li Z, Allen DB. Decreased energy expenditure is caused by abnormal body composition in infants with Prader-Willi syndrome. J Pediatr. 2003;143(3):372-376.

6. Festen DAM, Wevers M, Lindgren AC, et al. Mental and motor development before and during growth hormone treatment in infants and toddlers with Prader-Willi syndrome. Clin Endocrinol. 2008;68(6):919-925.

7. Siemensma EPC, Tummers-de Lind van Wijngaarden RFA, Festen DAM, et al. Beneficial effects of growth hormone treatment on cognition in children with Prader-Willi syndrome: a randomized controlled trial and longitudinal study. J Clin Endocrinol Metab. 2012;97(7):2307-2314.

8. Lo ST, Festen DAM, Tummers-de Lind van Wijngaarden RFA, Collin PJL, Hokken-Koelega ACS. Beneficial effects of long-term growth hormone treatment on adaptive functioning in infants with Prader-Willi syndrome. Am J Intellect Dev Disabil. 2015;120(4): 315-327.

9. Coupaye M, Lorenzini F, Lloret-Linares C, et al. Growth hormone therapy for children and adolescents with Prader-Willi syndrome is associated with improved body composition and metabolic status in adulthood. J Clin Endocrinol Metab. 2013;98(2):E328-E335.

10. Carrel AL, Myers SE, Whitman BY, Eickhoff J, Allen DB. Long-term growth hormone therapy changes the natural history of body composition and motor function in children with prader-willi syndrome. J Clin Endocrinol Metab. 2010;95(3):1131-1136.

11. Kuppens RJ, Bakker NE, Siemensma EPC, et al. Beneficial effects of gh in young adults with Prader-Willi syndrome: a 2-year crossover trial. J Clin Endocrinol Metab. 2016;101(11):4110-4116.

12. Damen L, Donze SH, Kuppens RJ, et al. Three years of growth hormone treatment in young adults with Prader-Willi syndrome: sustained positive effects on body composition. Orphanet J Rare Dis. 2020;15(1). 163 (2020).

13. Nagai T, Mori M. Prader-Willi syndrome, diabetes mellitus and hypogonadism. Biomed Pharmacother. 1999;53(10):452-454.

14. Butler JV, Whittington JE, Holland AJ, Boer H, Clarke D, Webb T. Prevalence of, and risk factors for, physical ill-health in people with Prader-Willi syndrome: a population-based study. Dev Med Child Neurol. 2002;44(4):248-255.

15. Fintini D, Grugni G, Bocchini S, et al. Disorders of glucose metabolism in Prader-Willi syndrome: results of a multicenter Italian cohort study. Nutr Metab Cardiovasc Dis. 2016;26(9):842-847.

16. Sode-Carlsen R, Farholt S, Rabben KF, et al. Body composition, endocrine and metabolic profiles in adults with Prader-Willi syndrome. Growth Horm IGF Res. 2010;20(3):179-184.

17. Crino A, Grugni G. Update on diabetes mellitus and glucose metabolism alterations in Prader-Willi syndrome. Curr Diab Rep. 2020;20(2):7.
18. Vogels A, Fryns JP. Age at diagnosis, body mass index and physical morbidity in children and adults with the Prader-Willi syndrome. Genet Couns. 2004;15(4):397-404.

19. Moller N, Jorgensen JO. Effects of growth hormone on glucose, lipid, and protein metabolism in human subjects. Endocr Rev. 2009;30(2):152-177.

20. Sanchez-Ortiga R, Klibanski A, Tritos NA. Effects of recombinant human growth hormone therapy in adults with Prader-Willi syndrome: a meta-analysis. Clin Endocrinol. 2012;77(1):86-93.

21. Jørgensen AP, Ueland T, Sode-Carlsen R, et al. Glucose homeostasis in adults with Prader-Willi syndrome during treatment with growth hormone: results from a 12-month prospective study. Growth Horm IGF Res. 2014;24(1):16-21.

22. Mogul HR, Lee PDK, Whitman BY, et al. Growth hormone treatment of adults with Prader-Willi syndrome and growth hormone deficiency improves lean body mass, fractional body fat, and serum triiodothyronine without glucose impairment: results from the United States multicenter trial. J Clin Endocrinol Metab. 2008;93(4):1238-1245.

23. Kuppens RJ, Bakker NE, Siemensma EP, Donze SH, Stijnen T, Hokken-Koelega AC. Metabolic health profile in young adults with Prader-Willi syndrome: results of a 2-year randomized, placebo-controlled, crossover GH trial. Clin Endocrinol. 2017;86(2):297-304.

24. de Lind van Wijngaarden RFA, Siemensma EPC, Festen DAM, et al. Efficacy and safety of long-term continuous growth hormone treatment in children with Prader-Willi syndrome. J Clin Endocrinol Metab. 2009;94(11):4205-4215.

25. Fredriks AM, van Buuren S, Burgmeijer RJF, et al. Continuing positive secular growth change in The Netherlands 1955-1997. Pediatr Res. 2000;47(3):316-323.

26. Fredriks AM, van Buuren S, Wit JM, Verloove-Vanhorick SP. Body index measurements in 1996-7 compared with 1980. Arch Dis Child. 2000;82(2):107-112.

27. Matthews DR, Hosker JP, Rudenski AS, Naylor BA, Treacher DF, Turner RC. Homeostasis model assessment: insulin resistance and beta-cell function from fasting plasma glucose and insulin concentrations in man. Diabetologia. 1985;28(7):412-419.

28. World Health Organization: Definition and diagnosis of diabetes mellitus and intermediate hyperglycemia: report of a WHO/IDF consultation, 2006. ISBN: 9789241594936

29. Bidlingmaier M, Friedrich N, Emeny RT, et al. Reference intervals for insulin-like growth factor-1 (igf-i) from birth to senescence: results from a multicenter study using a new automated chemiluminescence IGF-I immunoassay conforming to recent international recommendations. J Clin Endocrinol Metab. 2014;99(5):1712-1721.

30. Grundy SM, Cleeman JI, Daniels SR, et al. Diagnosis and management of the metabolic syndrome: an American Heart Association/ National Heart, Lung, and Blood Institute Scientific Statement. Circulation. 2005;112(17):2735-2752.

31. Sode-Carlsen R, Farholt S, Rabben KF, et al. Growth hormone treatment for two years is safe and effective in adults with Prader-Willi syndrome. Growth Horm IGF Res. 2011;21(4):185-190.

32. Tillin T, Hughes AD, Godsland IF, et al. Insulin resistance and truncal obesity as important determinants of the greater incidence of diabetes in Indian Asians and African Caribbeans compared with Europeans: the Southall And Brent REvisited (SABRE) cohort. Diabetes Care. 2013;36(2):383-393.

33. Snijder MB, Agyemang C, Peters RJ, Stronks K, Ujcic-Voortman JK, van Valkengoed IG. Case finding and medical treatment of type 2 diabetes among different ethnic minority groups: the HELIUS study. J Diabetes Res. 2017;2017:9896849.

34. Grugni G, Crinò A, Bedogni G, et al. Metabolic syndrome in adult patients with Prader-Willi syndrome. Nutr Metab Cardiovasc Dis. 2013;23(11):1134-1140. 
35. Butler MG, Smith BK, Lee J, et al. Effects of growth hormone treatment in adults with Prader-Willi syndrome. Growth Horm IGF Res. 2013;23(3):81-87.

36. Theodoro MF, Talebizadeh Z, Butler MG. Body composition and fatness patterns in Prader-Willi syndrome: comparison with simple obesity. Obesity (Silver Spring). 2006;14(10):1685-1690.

37. Sode-Carlsen R, Farholt S, Rabben KF, et al. One year of growth hormone treatment in adults with Prader-Willi syndrome improves body composition: results from a randomized, placebo-controlled study. J Clin Endocrinol Metab. 2010;95(11):4943-4950.
How to cite this article: Damen L, Grootjen LN, Donze SH, et al. Three years of growth hormone treatment in young adults with Prader-Willi Syndrome previously treated with growth hormone in childhood: Effects on glucose homeostasis and metabolic syndrome. Clin Endocrinol (Oxf). 2020;00:1-10. https://doi.org/10.1111/cen.14274 